\title{
Rare Disorder
}

National Cancer Institute

\section{Source}

National Cancer Institute. Rare Disorder. NCI Thesaurus. Code C4873.

A disease that affects fewer than 200,000 people in the United States. 